\title{
Proposing an Interdisciplinary, Communication-Focused Agenda for Cancer and Aging Researchers
}

\author{
Daniela B. Friedman ${ }^{1,2,5}$ - Sara Wilcox ${ }^{3}$. James R. Hebert ${ }^{2,4}$
}

Published online: 18 April 2015

(C) American Association for Cancer Education 2015

\section{Commentary}

Cancer is a complicated set of diseases that range widely in terms of anatomic site, histopathological characteristics, and virulence. Across this spectacular heterogeneity, cancer is primarily a disease of older people and the leading cause of death for men and women between 40 and 79 years of age [1]. There are multiple areas for which the biology of aging and cancer intersects where cooperative research could provide insight into potential mechanisms for the prevention and treatment of disease [2]. We argue that the most effective strategy for better understanding of processes related to cancer and aging is for researchers from both disciplines to approach their work collaboratively and to begin by focusing on improving communications about cancer and aging for diverse older adults and their families.

Adults $65+$ years old have increased from $4 \%$ of the total US population in 1900 to $13 \%$ in 2011 and are expected to

Daniela B. Friedman

dbfriedman@sc.edu

1 Department of Health Promotion, Education, and Behavior, Arnold School of Public Health, University of South Carolina, Columbia, SC 29208, USA

2 Statewide Cancer Prevention and Control Program, Arnold School of Public Health, University of South Carolina, Columbia, SC 29208, USA

3 Department of Exercise Science and Prevention Research Center, Arnold School of Public Health, University of South Carolina, Columbia, SC 29208, USA

4 Department of Epidemiology and Biostatistics, Arnold School of Public Health, University of South Carolina, Columbia, SC 29208, USA

5915 Greene Street, Room 235, Columbia, SC 29208, USA increase to $21 \%$ by 2050 [3]. Increased life expectancy, combined with a large cohort of aging "baby boomers," will result in doubling of this population over the next 25 years [4]. Even though cancer incidence and mortality rates have decreased over the past few decades, the declines have not been uniform across the aging population [5]. Costs for cancer care in the USA are projected to increase to $\$ 158$ billion by 2020 , reflecting a $27 \%$ increase from 2010 [6]. Guided by national research priorities $[7,8]$ and global trends in aging [9], academic and medical communities are becoming increasingly interested in applying strategies to reduce cancer incidence, disability, and suffering in older populations. In December 2013, the National Cancer Institute's Frontiers in Nutrition and Cancer Prevention Series [10] was focused specifically on common pathways for cancer and aging. In May 2014, the US Senate Special Committee on Aging held a hearing focused on the relationship of cancer and aging [11].

Cohen's [12] seminal 2007 article on the interface of cancer and aging provides recommendations for research in three main areas: basic biology, social and psychosocial, and clinical. These broad categories include multiple focus areas such as cancer screening and survivorship, barriers to participation in clinical trials and design of trials for older adults, cultural differences, family communication, tumor behavior, inflammation, and comorbidity and physical and cognition function. Cohen stressed that " ...effects of cancer and its treatment, for older patients and their families...should be targets for multidisciplinary collaborative research" (p. 1946) [12]. We propose that cancer and aging researchers collaborate to design studies that would provide evidence on the most effective means for communicating accurate and culturally appropriate messages about cancer prevention, control, and quality of life issues.

Health communication has emerged as an important field bringing together scholars whose innovative research 
questions and applied studies aim to improve strategies for reaching populations with health information and services with the ultimate goal of improving knowledge and outcomes [13]. Global aging trends will require a collaborative approach to clear communication with diverse older adults and their families about cancer and about research being conducted to improve quality of life for older populations. For effective collaborative study in aging and cancer communication, we recommend the following: (a) using or modifying conceptual frameworks from other disciplines as appropriate, (b) involving health-care providers in research, (c) conducting intergenerational or family-centered communication studies, and (d) creating culturally appropriate messaging through community-engaged research. The majority of the most important questions regarding cancer cause and prognosis will require the active participation of individuals-especially those from high-risk, susceptible subgroups.

Health communication research has been criticized for limited theoretical rigor; however, formative studies with older adults have been guided by social marketing principles [14], diffusion of innovations [15], or frameworks focused on dissemination and implementation [16]. Given the importance of clear and sensitive communication about cancer diagnosis and palliative care issues, frameworks from communications, public health, aging, or other disciplines that are guiding research on cancer and aging should incorporate ideas for improving patient-provider conversations and encounters that may be unique to older individuals.

Nussbaum and colleagues [17] stress the importance of studying interpersonal communication for the effective management of cancer among older individuals. For example, Ryan's Communication Predicament Model of Aging [18] demonstrates that communication based on negative stereotypes of aging incorporates modified speech that limits an older person's opportunity for satisfactory communication. Selective assertiveness, or communicating clearly without passively deferring to others or being aggressive toward them, has been proposed as a strategy for older adults to interrupt the communication predicament cycle [19]. Kahana and Kahana [20] also proposed a health-care communication framework demonstrating how a proactive behavior by older adults and their significant others can improve patient outcomes. Given the importance of significant others, family, and friends in making cancer-related decisions, this type of framework can be applied to cancer communication research with older adults, their families, and health-care providers (e.g., physicians, nurse practitioners, patient navigators). Given that providers still remain to be the most trusted source of health information for older individuals despite the proliferation of the Internet and social media [21], we need to engage them in this work. Providers and researchers must be mindful of the potential for older individuals and the social support networks in which they function to obtain and assimilate new information. Intervention studies have demonstrated patient satisfaction from effective communication with and counseling from health-care providers and from observing providers that are role modeling healthy behaviors [22].

Guided by models such as the ones described above, communication skill-building exercises and role-playing activities could be incorporated into research aiming to improve patientprovider communication about cancer prevention and control issues. For example, an intergenerational approach to prostate cancer and aging communication research has been recommended among African-American communities [23]. When individuals set out to make modifications in their lives to improve their health and quality of life, it is important to have medical information about their older relatives, on the one hand, and for them to consider the benefits that communication about family health history and hereditary conditions may have on their children, on the other. Communication interventions focused on cancers with a strong hereditary component should consider involving older and younger relatives and improving communication skills about cancer within families [24].

Much work has been done to explore cultural differences in the way older adults respond to and choose to receive health messages. For example, research with ethnically diverse older adults on prostate cancer communication needs resulted in a comprehensive framework of strategies, relevant communication channels and venues, and recommended message content for future dissemination [25]. While older adults' main source of health information has been their physician, distrust of providers, of the health-care system, and of medical research is still reported among racial and ethnic minority groups [24]. This underlines the need to consider and address these groups' perceptions through culturally relevant messaging and communication strategies. Collaborating from the outset with our target communities and partners by engaging them in the research process will ensure that we are developing and implementing approaches to communication about cancer and aging that they find meaningful [26]. An important corollary benefit would be the active engagement of individuals in research, especially those from racial and ethnic minority and underserved populations.

Finally, given the US Assistant Secretary of Health's 2013 remarks about comorbid conditions among older populations and the importance of the National Multiple Chronic Conditions (MCC) framework [27], it also will be important to examine the best strategies for communicating about cancer with older adults within the context of MCC. An effective interdisciplinary collaboration such as the one we propose requires open lines of communication, frequent interactions, and a willingness to understand the multifaceted elements of the collaborative enterprise and of the varied terminology and methodologies used by researchers across disciplines. Evaluating these partnerships will be important for guiding the work 
of scholars whose goal is to improve cancer communication and care with older populations. Approaching this work collaboratively, with the intention of creating a clear strategy for conducting significant research, developing theoretically guided messages, and engaging in dissemination activities with diverse team members will lead to increased understanding of cancer and aging and more effective communication with older adults.

Acknowledgments The authors were partially supported by the following grants: U48DP001936 and U48DP005000-01S2, the Cancer Prevention and Control Research Network, from the Centers for Disease Control and Prevention (CDC) Prevention Research Centers, and the National Cancer Institute (NCI) (Friedman, Hebert); U48DP001936, the Healthy Aging Research Network, from the CDC (Wilcox, Friedman); K05CA175239 from the NCI (Hebert); and U54CA153461, South Carolina Cancer Disparities Community Network II, from the NCI (Hebert and Friedman). The content of this article is solely the responsibility of the authors and does not necessarily represent the official views of the CDC or NCI.

\section{References}

1. Siegel R, Miller KD, Jemal A (2015) Cancer statistics, 2015. CA Cancer J Clin 65(1):5-29

2. Benz CC, Campisi J, Cohen HJ, Ershler WB, Irminger-Finger I (2007) Meeting report: translational research at the aging and cancer interface. Cancer Res 67(10):4560-4563

3. U.S. Census Bureau Housing and Household Economics Division Labor Force Statistics Branch, Holder KA, Clark SL. Working beyond retirement-age. 2008; http://www.census.gov/people/ laborforce/publications/Working-Beyond-Retirement-Age.pdf. Accessed 9 Jan 2014

4. U.S. Census Bureau (2005) 65+ in the United States: 2005. U.S. Government Printing Office, Washington

5. U.S. Department of Health and Human Services Centers for Disease Control and Prevention and National Cancer Institute. United States Cancer Statistics: 1999-2010 incidence and mortality web-based report. www.cdc.gov/cancer/npcr/uscs. Accessed 1 Aug 2014

6. Mariotto AB, Yabroff KR, Shao Y, Feuer EJ, Brown ML (2011) Projections of the cost of cancer care in the United States: 20102020. J Natl Cancer Inst 103(2):117-128

7. United States Department of Health and Human Services. Healthy people 2020: dementias, including Alzheimer's disease. 2010; http://www.healthypeople.gov/2020/topicsobjectives2020/ overview.aspx?topicid=7. Accessed 9 Jan 2014

8. United States Department of Health and Human Services. Healthy people 2020: cancer objectives. 2010; http://www.healthypeople. gov/2020/topicsobjectives2020/objectiveslist.aspx?topicId=5. Accessed 1 Mar 2014

9. Pew Research Center. Attitudes about aging: a global perspective. 2014; http://www.pewglobal.org/files/2014/01/Pew-ResearchCenter-Global-Aging-Report-FINAL-January-30-20141.pdf. Accessed 1 Sep 2014

10. National Cancer Institute Division of Cancer Prevention. Can nutrition simultaneously affect cancer and aging? http://prevention. cancer.gov/programs-resources/groups/ns/webinars/20131204. Accessed 1 Sep 2014
11. United States Senate Special Committee on Aging. The fight against cancer: challenges, progress, and promise. 2014 May 7; http://www.aging.senate.gov/hearings/the-fight-against-cancerchallenges-progress-and-promise. Accessed 1 Oct 2014

12. Cohen HJ (2007) The cancer aging interface: a research agenda. J Clin Oncol 25(14):1945-1948

13. Hannawa AF, Kreps GL, Paek HJ, Schulz PJ, Smith S, Street RL Jr (2014) Emerging issues and future directions of the field of health communication. Health Commun 29(10):955-961

14. Friedman DB, Hooker SP, Wilcox S, Burroughs EL, Rheaume CE (2012) African American men's perspectives on promoting physical activity: "we're not that difficult to figure out!". J Health Commun 17(10):1151-1170

15. Friedman DB, Laditka JN, Hunter R et al (2009) Getting the message out about cognitive health: a cross-cultural comparison of older adults' media awareness and communication needs on how to maintain a healthy brain. Gerontologist 49(Suppl 1):S50-S60

16. Ory MG, Altpeter M, Belza B, Helduser J, Zhang C, Smith ML (2014) Perceptions about community applications of RE-AIM in the promotion of evidence-based programs for older adults. Eval Health Prof 38:15-20

17. Nussbaum JF, Baringer O, Kundrat A (2003) Health, communication, and aging: cancer and older adults. Health Commun 15(2): 185-192

18. Ryan EB, Hummert ML, Boich L (1995) Communication predicaments of aging: patronizing behavior toward older adults. J Lang Soc Psychol 13:144-166

19. Ryan EB, Anas A, Friedman DB (2006) Evaluations of older adult assertiveness in problematic clinical encounters. J Lang Soc Psychol 25(2):129-145

20. Kahana E, Kahana B (2003) Patient proactivity enhancing doctorpatient-family communication in cancer prevention and care among the aged. Patient Educ Couns 50(1):67-73

21. Stein PS, Aalboe JA, Savage MW, Scott AM (2014) Strategies for communicating with older dental patients. J Am Dent Assoc 145(2):159-164

22. Friedman DB, Freedman DA, Choi SK et al (2014) Provider communication and role modeling related to patients' perceptions and use of a federally qualified health center-based farmers' market. Health Promot Pract 15(2):288-297

23. Jackson DD, Owens OL, Friedman DB, Hebert JR (2014) An intergenerational approach to prostate cancer education: findings from a pilot project in the southeastern USA. J Cancer Educ 29(4):649-656

24. Owens OL, Jackson DD, Thomas TL, Friedman DB, Hebert JR (2013) African-American men's and women's perceptions of clinical trials research: focusing on prostate cancer among a high risk population in the South. J Health Care Poor Underserved 24(4): $1784-1800$

25. Friedman DB, Corwin SJ, Rose ID, Dominick GM (2009) Prostate cancer communication strategies recommended by older AfricanAmerican men in South Carolina: a qualitative analysis. J Cancer Educ 24(3):204-209

26. Greiner KA, Friedman DB, Adams SA et al (2014) Effective recruitment strategies and community-based participatory research: Community Networks Program Centers' recruitment in cancer prevention studies. Cancer Epidemiol Biomark Prev 23:416-423

27. United States Department of Health and Human Services. Multiple chronic conditions: a strategic framework. 2010 December; http:// www.hhs.gov/ash/initiatives/mcc/mcc_framework.pdf. Accessed 2 Jan 2015 